therapy, physiotherapy and occupational therapy have a long tradition in their association with the practice of medicine. They all have standards of training and a code of ethics which is acceptable to the medical profession and which permits them to function within a medical milieu to the advantage of patients.

As with any branch of medical practice, their functions are under constant scrutiny, not only in their ethical and professional aspects, but in their efficacy. In pharmacotherapy, there are rigid standards for clinical trials, and even when a 'breakthrough' in treatment is apparent, such as the use of lithium salts in manic-depressive psychosis, a report on its prophylactic value by Baastrup et al. (1967), which many would have regarded as reasonable, was severely attacked by Blackwell and Shepherd (1968) and Lader (1968) mainly on the methodology of the trial. The original authors came back with a more rigorous trial (Baastrup et al., 1970; Angst et al., 1970) and vindicated their earlier claims.

Psychotherapy, which can mean anything from a friendly chat to a full-scale analysis, is also under scrutiny, and the recent work by Candy et al. (1972) and Cawley et al. (1973), while not proving its ineffectiveness, has cast doubts on a generally held belief that there are very large numbers of people who would benefit from psychotherapy but do not receive it. These authors' studies would suggest that, on the contrary, there are many people receiving psychotherapy who do not require it. As I have said in my previous letter, medicine does not accept the status quo, but questions, modifies and discards even the most sacred cults.

I do not accept that what the public wants must necessarily be for the public good. There is too much evidence to the contrary; alcohol, drugs, gambling and promiscuity are obvious examples. Medicine does not cater for public demand; it is frequently its duty to resist such demands.

One last point. I agree that at present there are a host of agencies which are used in community psychiatry, but the fact that they are used does not necessarily mean that they are essential or even of value. More and more psychiatrists support the view that the community nurse model is more relevant to the present needs of the patient in the community than the existing models. One day there will be a reckoning; the medical practitioner, if he is true to his profession, will anticipate that day.

Myre Sn.

The Queen Elizabeth Hospital, Queen Elizabeth Medical Centre, Edgbaston, Birmingham, Br5 2 TH.
REFERENGES

Angst, J., Wers, P., Gror, P., Banstrup, P. C. \& ScHоU, M. (1970) Lithium prophylaxis in recurring affective disorders. British fournal of Psychiatry, 116, 604-14.

BaAstrup, P. C. \& Schou, M. (1967) Lithium as a prophylactic agent; its effect against recurrent depression and manic depressive psychosis. Archives of General Psychiatry, 16, 162-72.

Brackwell, B. \& Shepherd, M. (1968) Prophylactic lithium; another therapeutic myth? An examination of the evidence to date. Lancet, $i$, 968-71.

Candy, J., Balpoor, H. G., Cawley, R. H., Hudeband, H. P., Malan, D. H., Marks, I. M. \& Wilson, J. (1972) A feasibility study for a controlled trial of formal psychotherapy. Lancet, $i, 968-71$.

Cawzey, R., Candy, J., Malan, D. \& Marks, I. (1973) Dynamic psychotherapy: can it be evaluated? Psychological Medicine, 2, 345-62.

LADRR, M. H. (1968) Prophylactic lithium? Lancet, ii, 103.

\section{BURDEN RESEARCH MEDAL AND PRIZE}

DeAR SIR,

Entry for the Burden Research Medal and Priza is open to all registered medical practitioners who are working in the field of mental subnormality in the United Kingdom or Republic of Ireland.

The award for 1975, total value $£ 250$, may be presented at Stoke Park Hospital on or about I April 1975, for outstanding research work which has been published, accepted for publication or presented as a paper to a learned society during the three-year period ending 31 December 1974.

Five copies of the paper or papers, with application form, should be submitted to the Secretary of of the Burden Trust by 10 January 1975.

Further information and application forms are available from the Secretary, Burden Trust, 16 Orchard Street, Bristol, BS 1 5EA.

\section{W. A. Heaton-Ward.}

\section{A COMPILATION OF PAPERS FOR THE USE OF POSTGRADUATE STUDENTS OF PSYCHIATRY}

Dear SiR,

The Clinical Tutors' Sub-Committee, through the courtesy of John Wyeth and Brother, has prepared a fourth printing of the compilation of selected papers in psychiatry for postgraduate students, the previous printings now being exhausted. A limited number are available; those wanting copies should write to John Wyeth and Brother Ltd., Huntercombe Lane South, Taplow, Maidenhead, Berks.

Brian Barraclough. Bernard HeIne. ANDREW SMTth. 